\title{
Trends in surveillance data of influenza virus in Tehran before decreasing dispatch of Iranian Hajj pilgrims to Mecca
}

\author{
Maryam Esghaei ${ }^{1}$, Mohsen Moghoofei ${ }^{1}$, Mohsen Keshavarz ${ }^{1}$, Hossein Keyvani ${ }^{* 1}$ \\ Farah Bokharaei-Salim ${ }^{1,2}$, Mohamad Farahmand ${ }^{3}$, Seyed Hamidreza Monavari ${ }^{1}$
}

Received: 3 July 2017

Published: 21 May 2018

\begin{abstract}
Background: Respiratory infections, especially viral infections, are the most prevalent infection affecting Hajj pilgrims. Commonly 3 major human influenza viruses (A/H1N1, A/H3N2, and B) are responsible for these morbidities. The present study was conducted to develop a statistical report on human influenza in Hajj pilgrims.

Methods: Nasal and throat samples were collected from 232 returning Iranian pilgrims in hospitals of IUMS. All samples were kept in the refrigerator at $4{ }^{\circ} \mathrm{C}$ and stored at $-70{ }^{\circ} \mathrm{C}$ until RNA extraction. RNA extraction was performed by QIAamp viral RNAmini kits (QIAGEN, Hilden, Germany) and influenza viruses were detected by TaqMan RT-PCR.

Results: Participants included 115 (49.5\%) male and 117 (50.5\%) female patients, with the age range of 10 to 93 years (mean: 53 years). The pandemic and seasonal influenza A (H1N1) virus were detected in $2(0.8 \%)$ and $20(8.6 \%)$ pilgrims, respectively, and also influenza B was identified in 1 person $(0.4 \%)$.

Conclusions: Since the probability of an influenza pandemic has been anticipated for the coming years, it seems necessary to plan a continuous monitoring of large gatherings like Hajj and conduct statistical studies in the region. Moreover, material surveillance in humans needs to be boosted. Therefore, results of influenza research can be important for developing WHO reports.
\end{abstract}

Keywords: Influenza, Hajj, Pilgrim, Iran

Copyright@ Iran University of Medical Sciences

Cite this article as: Esghaei M, Moghoofei M, Keshavarz M, Keyvani H, Bokharaei-Salim F, Farahmand M, Monavari SH. Trends in surveillance data of influenza virus in Tehran before decreasing dispatch of Iranian Hajj pilgrims to Mecca. Med J Islam Repub Iran. 2018(21 May);32:41. https://doi.org/10.14196/mjiri.32.41

\section{Introduction}

Influenza A is an enveloped negative-strand RNA virus with 8 segmented genomes, which are classified as belonging to the orthomyxovirus family (1-3). This virus is a circulating pathogen that causes morbidity and mortality worldwide among humans $(4,5)$. Based on surface glycoproteins, this virus is divided into 6 genera, of which 3 affect humans: Influenza virus A, B, and C $(1,6-8)$. The diagnostic tests for this virus, which include viral isolation, biopsy or autopsy tissue section, rapid diagnostic tests, se-

Corresponding author: Dr Hossein Keyvani, keyvanlab@yahoo.com keyvani.h@iums.ac.ir

1. Department of Virology, School of Medicine, Iran University of Medical Sciences, Tehran, Iran.

2. HIV Laboratory of National Center, Vice Chancellor for Health, Iran University of Medical Sciences, Tehran, Iran.

3. Department of Virology, Faculty of Public Health, Tehran University of Medical Sciences, Tehran, Iran. rologic methods, and confirmation tests, include immunohistochemical techniques or in situ hybridization (9). Haemagglutination test is used to quantify the titer of influenza virus and it is based on binding of the HA antigen with the sialylated glycans of erythrocytes.

Spread of communicable diseases, especially respiratory infections, is facilitated in large and dense crowds. Annually, more than 3 million pilgrims from $>160$ countries, including thousands from Iran, gather in Saudi Arabia to perform Hajj, which is one of the largest gatherings in the

$\uparrow$ What is "already known" in this topic:

Outbreaks of influenza viruses that spread via respiratory route are common among Hajj pilgrims. Since a few years ago, pilgrims have been recommended to take influenza vaccine before dispatch to Mecca. Few studies in Iran reported different information that showed vaccination coverage has been satisfying in recent years

\section{$\rightarrow$ What this article adds:}

The present study investigated the prevalence of influenza-like illness (ILI) in Hajj pilgrims after returning to Tehran. So, surveillance data of influenza virus in Tehran was examined to report the rate of ILI against influenza vaccine uptake among Iranian Hajj pilgrims over the last 2 years. 
Table 1. Primers and probes sequence used in this study

\begin{tabular}{lcc}
\hline \hline Primers \& probes & Position $(\mathrm{bp})$ & Sequences $\left(5^{\prime}>3^{\prime}\right)$ \\
\hline Flu A(H1N1)forward & $393-416$ & TGAGATATTCCCCAAGACAAGTTC \\
Flu A(H1N1) reverse & $489-467$ & TTTGTAGAAGCTTTTTGCTCCAG genes \\
Flu A(H1N1) probe & $426-451$ & TCATGACTCGAACAAAGGTGTAACGG \\
Flu A(H3N2)forward & $744-770$ & CTATTGGACAATAGTAAAACCGGGRGA \\
Flu A(H3N2)reverse & $898-921$ & GTCATTGGGRATGCTTCCATTTGG \\
Flu A(H3N2) probe & $799-821$ & AAGTAACCCCKAGGAGCAATTAG \\
Flu B forward primer & $43-59$ & GGAGCAACCAATGCCAC \\
Flu B reverse primer & $138-147$ & GTTTAGGCGGTCTTGACCAG \\
Flu B probe & $61-80$ & ATAAACTTTGAAGCAGGAAT \\
Flu A) forward & $1393-1416$ & CCGAGGTCGAAACGTATGTTCTCTCTATC \\
Flu A reverse & $1567-1589$ & TGACAGAATTGGTCTTGTCTTTAGCCATTCCA \\
Flu A probe & $1424-1451$ & ATCTCGGCTTTGAGGGGGCCTG \\
\hline
\end{tabular}

world. The pilgrims move from one place to another in Mecca to complete Hajj ritual (10). Thus, this gathering can increase the risk of public health issues, such as food-borne diseases and respiratory infections, particularly of the pandemic influenza $\mathrm{A} / \mathrm{H} 1 \mathrm{~N} 1, \mathrm{~A} / \mathrm{H} 3 \mathrm{~N} 2$, and $\mathrm{B}$. A high rate of attack of seasonal influenza has been reported among the Iranian Hajj pilgrims (11). A few studies have reported an epidemiology of influenza A (H1N1, H3N2) and B infection among the Hajj pilgrims. The first aim of this study was to provide a statistical report of human influenza A viruses $(\mathrm{H} 1 \mathrm{~N} 1, \mathrm{H} 3 \mathrm{~N} 2)$ and influenza B viruses of Iranian pilgrims in Hajj in hospitals of Iran University of Medical Sciences (IUMS) during 2013 and 2015. The second aim was to assess pilgrim's beliefs and intentions on taking the vaccine to prevent influenza during Hajj.

\section{Methods}

\section{Patients' enrolment and specimen preparation}

This was a cross-sectional study and the target population was 232 returning Iranian pilgrims during 2013, 2014, and 2015 in Tehran province. Pilgrims had acute respiratory infection (ARI) and symptoms including fever, cough, and sore throat. The protocol was approved by the ethical research committees at IUMS.

In the study, patients were interviewed by investigators who used a standardised questionnaire and filled out a form about medical history, clinical data, and demographic characteristics. The interviewer described the voluntary nature of participation and provided information on antiviral drugs and influenza vaccine.

All specimens were taken from nose and throat by Dacron swab and collected into sampling media (Hank's Balanced Salt Solution) at the laboratory, then, they were kept in the refrigerator at $4{ }^{\circ} \mathrm{C}$ and stored at $-70^{\circ} \mathrm{C}$ until RNA extraction.

\section{RNA extraction}

RNA extraction was done by QIAamp viral RNAmini kits (QIAGEN, Hilden, Germany), according to the kit instructions, and all extracts were stored at $-80{ }^{\circ} \mathrm{C}$. Primers and probes were designed according to available sequences in the Gene Bank database of the National Centre for Biotechnology Information (NCBI) using Primer3plus (http:// primer3plus.com/).

\section{$R T-P C R$}

The amplification process was done by TaqMan RT-PCR master mix ReagentsQIAamp viral RNAmini kits (QIAGEN, Hilden, Germany), and tests were conducted with Corbett 6000 Rotor-Gene system (Corbett, Victoria, Australia). Each reaction included $4 \mu \mathrm{L}$ of extracted RNA mixed with $16 \mu \mathrm{L}$ of master mix, which included $2 x \mathrm{RT}$ PCR Quick Master Mix, nuclease-free water, control primer forward and reverse, and $50 \mathrm{mMMn}(\mathrm{OAc}) 2$. All samples were tested by separated primer and probe sets to identify $\mathrm{H} 1 \mathrm{~N} 1$ and $\mathrm{H} 3 \mathrm{~N} 2$ (Table 1). According to CDC protocol, RT-PCR cycling included $42{ }^{\circ} \mathrm{C}$ for 30 minutes, 7 minutes for Taq activation at $95{ }^{\circ} \mathrm{C}$, then, $95^{\circ} \mathrm{C}$ for $15 \mathrm{sec}-$ onds, and an annealing extension step with temperatures, ranging from 50 to $65^{\circ} \mathrm{C}$ for 30 seconds for 45 cycles.

Ethics

This research was approved by Ethics Committee of Iran University of Medical Sciences (IUMS) (project number: 93-01-30-24468).

\section{Statistical analysis}

In this study, we used Fisher's exact test to determine the differences in proportions. Statistical computations were performed by SPSS 18.0 for Windows, GraphPad 5, and Excel, and p-value $<0.05$ was considered significant.

\section{Results}

We enrolled 232 Iranian pilgrims in this study during 2013 to 2015 , of them $115(49.5 \%)$ were male and 117 $(50.5 \%)$ female, and their age ranged from 10 and 93 years (mean: 53 years). The prevalence of seasonal H1N1 influenza (18 persons; $14.1 \%)$ was significantly more $(\mathrm{p}=0.02)$. In 2013 compared to 2014 (5 persons; 4.8\%). Detailed description of characterization and comparison of these years is presented in Tables 2 and 3 and Fig. 1. Data analysis

Table 2. Distribution subtypes of influenza in 2013 and 2014-2015

\begin{tabular}{lccccc}
\hline Influenza & \multicolumn{2}{c}{ Year 2013 } & \multicolumn{2}{c}{ Year 2014-2015 } & \\
\cline { 2 - 4 } subtype & Positive & Negative & Positive & Negative & \\
A/H3N2 & 0 & 128 & 0 & 104 & 1.01 \\
Seasonal H1N1 & 15 & 113 & 5 & 99 & 0.06 \\
Pandemic H1N1 & 2 & 126 & 0 & 104 & 0.07 \\
Flu B & 1 & 127 & 0 & 104 & 0.08 \\
\hline
\end{tabular}




\begin{tabular}{|c|c|c|c|c|c|c|c|c|c|}
\hline Sex & Mean of Age & $\mathrm{n}$ & H1N1 Pandemic & H1N1 Seasonal & $\mathrm{H} 3 \mathrm{~N} 2$ & Flu B & Fever & Cough & Myalgia \\
\hline Male & 63.00 & 11 & 1 & 10 & 0 & 0 & 8 & 8 & 5 \\
\hline Female & 46.41 & 12 & 1 & 10 & 0 & 1 & 7 & 8 & 11 \\
\hline Total $(\%)$ & 54.34 & $23(100)$ & $2(8.7)$ & $20(86.9)$ & $0(0)$ & $1(4.3)$ & $15(65.2)$ & $16(69.6)$ & $16(69.6)$ \\
\hline
\end{tabular}

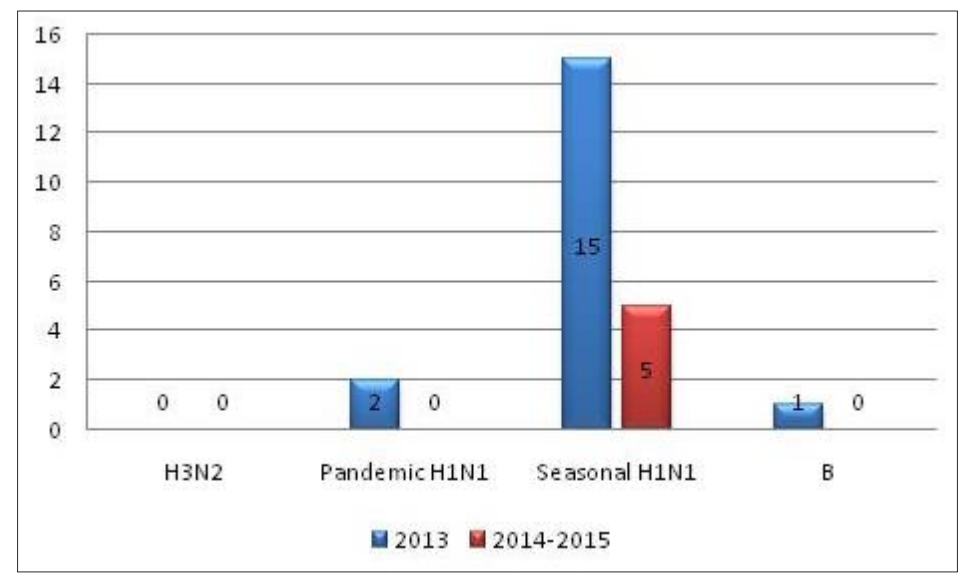

Fig. 1. Influenza distribution in Hajj pilgrims in Tehran in 2013 and $2014-2015$

showed that 11 of 115 males and 12 of 117 females were positive, of which 2, 20, and 1 had pandemic H1N1, seasonal $\mathrm{H} 1 \mathrm{~N} 1$, and influenza B, respectively. Also, results indicated that the mean age of influenza positive and negative patients was 53.59 and 54.34 years, respectively. Seasonal influenza vaccination coverage for the preceding Iranian Hajj Pilgrims was $100 \%$, moreover, influenza vaccine is administered to all the Hajj Pilgrims before travelling in the Islamic Republic of Iran.

\section{Discussion}

Upper respiratory tract (URT) infection is a major health problem during Hajj. The exact prevalence of URT infection among pilgrims is not known. This infection was estimated to range $20 \%$ to $80 \%$ depending on method of detection (12). One of the most important global causes of morbidity and mortality is influenza, resulting in an estimated 3 to 5 million cases of severe influenza illness and 250000 to 500000 deaths worldwide annually. Past studies have demonstrated that influenza viruses are the most common viral infection among Hajj pilgrims and vaccination cannot efficiently prevent this infection. Over more than 2 consecutive years, we conducted a cross-sectional study of influenza in respiratory specimens collected from Iranian Hajj pilgrims after leaving Saudi Arabia for Tehran. Our study provided a new insight into the pandemic (H1N1) influenza and influenza virus A(H3N2) in Tehran. Also, in this study, we checked both seasonal and pandemic H1N1, H3N2, and influenza B viruses in Hajj pilgrims. Rate of pH1N1 was very low among pilgrims (about $0.86 \%(p>0.05)$ ), seasonal H1N1 was $8.6 \%(p=0.06), H 3 N 20 \%(p>0.05)$, and influenza B $0.43 \%(p>0.05)$. Prevalence of all influenza subtypes was higher in 2013 than in 2014 and 2015 (p>0.02). Reduction in the prevalence of these influenza subtypes in 2014 compared to 2013 can be due to the increase in levels of personal hygiene or prevention methods, such as vaccination. The attack rate of seasonal influenza in our study was $8.6 \%(20 / 232)$, which is similar to previous studies conducted in Iran, the UK, and Saudi Arabia (5). Due to special circumstances in Hajj, such as large number of pilgrims in a small area, it is not easy to prevent the transmission of respiratory infections, including influenza.

Moattari et al. in Shiraz (2012) reported the prevalence of influenza in pilgrims. Using virus culture, we found that $25(9.1 \%)$ pilgrims had influenza: influenza $B(n=17)$, influenza A (H3N2) $(n=8)$, and pandemic H1N1 $(n=5)$. Moreover, using RT-PCR method, we also found that 33 (12\%) pilgrims had influenza: influenza $B(n=20)$, influenza A $(\mathrm{H} 3 \mathrm{~N} 2)(\mathrm{n}=8)$, and pandemic H1N1 $(\mathrm{n}=5)(11)$. In a study by Moattari et al., the attack rate of seasonal influenza was $10.2 \%$, and this result was similar to that of other studies conducted in previous years in the UK, Iran, and Saudi Arabia (11).

Another study done by Rashid et al. (2005) reported the rate of influenza virus in UK pilgrims as follow: Influenza A (H3) was $54 \%$ of the virus-positive samples, influenza B $19 \%$, and influenza A (H1) 3\% (12). In another study, rate of viral respiratory infections was compared between Saudi and UK pilgrims by Rashid et al. Results of this study were as follow: rate of influenza virus infection in both geographical regions was similar (10\%) (13). Memish et al. (2009) reported that the prevalence of influenza A virus was $0.2 \%$ in Saudi Arabia (14).

In 2009, Ziyaeyan et al., by PCR, reported the incidence of acquired $\mathrm{H} 1 \mathrm{~N} 1$ to be $1.6 \%$ among returning Iranian pilgrims during the Hajj season (15). The difference in prevalence can be due to increased levels of personal hygiene or prevention methods such as vaccination.

Data analysis revealed that the rate of influenza increased in 2013 compared to 2014 and 2015, which is one of the reasons for the reduced deployment in Hajj due to political problems.

Finally, the results of this study and similar studies could improve hygiene levels and reduce disease and mortality 
during Hajj.

Results of researches on influenza can be important for developing WHO reports, but there is still a need for support and enhancement. To improve systematic surveillance in humans, surveillance data should be presented not only within each country but also internationally.

\section{Conclusion}

Study of the frequency of seasonal and pandemic influenza in Hajj pilgrims is necessary for annual monitoring. Despite vaccination, seasonal influenza has affected many of the symptomatic Iranian pilgrims. However, other effective factors in the prevention of influenza disease should not be ignored. On the other hand, due to political reasons, pilgrims dispatching to Mecca was decreased in Iran, so the preliminary results of the present study cannot be extrapolated to all pilgrims because this work was part of a largescale study that should be continued in the following years.

\section{Acknowledgement}

The authors would like to thank all study participants, Keyvan Virology Laboratory in Tehran, and the Virology Department of Iran University of Medical Sciences for their collaboration on this project.

\section{Financial disclosure}

The Vice Chancellor of Research of Iran University of Medical Sciences financially supported this study.

\section{Funding/support}

This study was funded by the Research Deputy of Iran University of Medical Sciences (IUMS) (Grant no = 24468).

\section{Conflict of Interests}

The authors declare that they have no competing interests.

\section{References}

1.Fraaij PL, Heikkinen T. Seasonal influenza: the burden of disease in children. Vaccine. 2011;29:7524-8.

2.Fotouhi F, Farahmand B, Heidarchi B, Esghaei M, Rafati S, Kheiri MT. In Vitro Evaluation of Influenza M2 and Leishmania major HSP70 (604-221) Chimer Protein. Jundishapur J Microbiol. 2014;7:1-6.

3.Kaynar L, Şivgin S, Başpinar O, Kurnaz F, Yildirim A, Metan G. Two cases of H1N1 influenza infection as the initial presentation of acute leukemia. Turk J Med Sci. 2011;41:363-7.

4.Li JH, Wang RQ, Guo WJ, Li JS. Efficacy and safety of traditional Chinese medicine for the treatment of influenza A (H1N1): A metaanalysis. J Chin Med Assoc. 2016;79:281-91.

5.Palache A, Oriol-Mathieu V, Abelin A, Music T. Seasonal influenza vaccine dose distribution in 157 countries (2004-2011). Vaccine. 2014;32:6369-76.

6.Hay AJ, Gregory V, Douglas AR, Lin YP. The evolution of human influenza viruses. Philos Trans R Soc Lond B Biol Sci. 2001;356: 186170.

7.Yavarian J, Jandaghi NZS, Naseri M, Azad TM. Characterization of variations in $\mathrm{PB} 2$, NS1, M, neuraminidase and hemagglutinin of influenza A (H3N2) viruses in Iran. Jundishapur J Microbiol. 2014;7: $1-4$.

8.Sevencan F, Ertem MM ,Özçullu N, Dorman V, Ormanli A, Kubat NK, Albayrak N, Altaş AB. Retrospective evaluation of laboratoryconfirmed and recovered cases of influenza A (H1N1) v. Turk J Med Sci. 2011;41:647-56.
9.Taubenberger JK, Layne SP. Diagnosis of influenza virus: coming to grips with the molecular era. Mol Diagn. 2001;6:291-305.

10.Deris ZZ, Hasan H, Sulaiman SA, Wahab MSA, Naing NN, Othman NH. The prevalence of acute respiratory symptoms and role of protective measures among Malaysian Hajj pilgrims. J Travel Med. 2010;17:82-8.

11.Moattari A, Emami A, Moghadami M, Honarvar B. Influenza viral infections among the Iranian Hajj pilgrims returning to Shiraz, Fars province, Iran. Influenza Other Respir Virus. 2012;6:77-9.

12.Al-Tawfiq JA, Zumla A, Memish ZA. Respiratory tract infections during the annual Hajj: potential risks and mitigation strategies. Curr Opin Pulm Med. 2013;19:192-7.

13.Rashid H, Shafi S, Booy R, El Bashir H, Ali K, Zambon M, Memish Z, Ellis J, Coen PG, Haworth E. Influenza and respiratory syncytial virus infections in British Hajj pilgrims. Emerg Health Threats J. 2008;1:1-5.

14.Memish ZA, Assiri AM, Hussain R, Alomar I, Stephens G. Detection of respiratory viruses among pilgrims in Saudi Arabia during the time of a declared influenza A (H1N1) pandemic. J Travel Med. 2012;19: 15-21.

15.Ziyaeyan M, Alborzi A, Jamalidoust M, Moeini M, Pouladfar GR, Pourabbas B, Namayandeh M, Moghadami M, Bagheri-Lankaran K, Mokhtari-Azad T. Pandemic 2009 influenza A (H1N1) infection among 2009 Hajj Pilgrims from Southern Iran: a real-time RT-PCRbased study. Influenza Other Respir Virus. 2012;6:80-4. 